\title{
Compression Auto Ignition Control in a 2-Stroke Barrel-Type Opposed- Piston Engine
}

\author{
Rafał Pyszczek, Paweł Mazuro, Andrzej Teodorczyk \\ Warsaw University of Technology \\ Institute of Heat Engineering \\ Nowowiejska 21/25, 00-665 Warsaw, Poland \\ rafal.pyszczek@itc.pw.edu.pl; pmazuro@itc.pw.edu.pl; ateod@itc.pw.edu.pl
}

\section{Extended Abstract}

The possibility of achieving high thermal efficiency brings opposed-piston (OP) engines back into interest of research centers. The main advantage of such design is that combustion chamber is formed between moving pistons - there is no additional cylinder head to be cooled which directly results in an increased thermal efficiency. If made as a 2-stroke, the possibility of uniflow scavenging arises together with lower engine cost due to removal of unnecessary parts, like camshafts or poppet valves. Furthermore, engine operation in a homogeneous charge compression ignition (HCCI)/controlled autoignition (CAI) mode at high compression ratios (CR) raises a possibility of reaching even higher efficiencies and very low emissions [1].

There are several types of OP engine configurations (cranckless, single crankshaft, multiple crankshaft, rotary or barrel) [2]. The barrel type OP engine is of particular interest for the authors because of its robust design, not many moving parts (high mechanical efficiency) and relatively easy incorporation of a variable compression ratio (VCR) [3]. This kind of experimental 2-stroke engine equipped with the VCR is currently under development at Warsaw University of Technology. The VCR is necessary to enable engine control at CAI operation mode. In addition, the engine will be equipped with a water injection system for charge cooling which is another measure to control the CAI combustion process. The injected water is supposed to cool the charge in the cylinder through the evaporation and retard the auto-ignition (AI) in case of CAI mode or to prevent knock in case of spark ignition (SI) mode allowing engine operation at higher compression ratios. Although the idea of HCCI/CAI combustion is desirable because of possible benefits in terms of efficiency and emissions, it is also very challenging to implement in an internal combustion engine. Therefore, numerical simulations can become a useful tool for better understanding of the combustion process and can shorten the time span for engine development.

The aim of this study is to investigate a possibility of CAI control in a 2-stroke barrel type OP direct injection engine fueled with a gasoline. To that end, a 3D CFD numerical simulations of the scavenging and combustion processes were performed with use of the AVL Fire solver that is based on a Finite Volume Method (FVM) discretization and offers a number of tools dedicated to numerical simulations of working processes in internal combustion engines [4]. The VCR and water injection were considered for the ignition timing control. Hence, several cases were calculated with different engine compression ratios and different amount of injected water, varying in a range of $0-100 \%$ of the fuel mass. The influence of the VCR and water injection on the ignition timing were determined and their application in the real engine was discussed.

\section{References}

[1] H. Zhao, HCCI and CAI engines for the automotive industry. Woodhead Publishing, 2007

[2] M. Flint, Opposed Piston Engines: Evolution, Use, and Future Applications. Warrendale: SAE International, 2010

[3] P. Mazuro, T. Rychter, and A. Teodorczyk, "Piston engines with cylinder axis parallel to drive shaft axis - classification and review," Journal of KONES Powertrain and Transport, vol. 13, no. 3.

[4] AVL Fire Manual v2014 